\title{
Tactics and the Three Elements of Strategy
}

Strategy is a philosophy, an overall ideology offering guidance, while tactic is an action plan or action plans, a project proposal, and the former is guiding the latter.

I found that to understand what a strategy is; it is necessary to figure out how tactics and strategies are related? What is the relationship between tactic and the three elements of strategy concept? In fact, I gained a better understanding of what is a strategy after finishing writing this chapter.

\subsection{A Military Example}

Let us have a look at a battle between Yuanzhang Zhu, the first emperor of China's Ming Dynasty (1368-1644) in his early days and Youliang Chen, a warlord.

When Yuanzhang Zhu was 17 years old, his parents and brother died of famine, and he had to be a monk in the temple and begged for a living. Three years of wandering gave him rich knowledge of the geographical conditions and local customs in the west of Huaihe River. Later, Zhu's friend since childhood, who was in the rebel army persuaded him to join them. Therefore, Zhu went to Haozhou City and fought under the command of Zixing Guo. Convinced that he outsmarted Guo too much, Zhu left and founded his own army. In 1356, Zhu took Yingtian City (now Nanjing city, the capital of Jiangsu province, China) and chose it as the capital. To the west of Yingtian was the territory of Shouhui $\mathrm{Xu}$, who was soon usurped by his subordinate, Youliang Chen, an ambitious and more capable man. Chen took over the troops of more men than Zhu, including a naval force best equipped in China at the time. In December 1359, Zhu's subordinate, vanguard of the general's palace, Yuchun Chang, buried 3000 captives alive after the battle of capturing Chizhou City on Chen's territory. Enraged by that Youliang Chen 
decided to fight back. Chen led the most powerful fleet in the country for Yingtian City, broke the natural barrier of Yangtze River, and occupied Zhu's military fortress-Caishi, breaking Yingtian's natural defense-Taiping.

What should Yuanzhang Zhu do now? For him, a strategy was necessary in this battle, and this strategy was problem-oriented.

Major problem: Yingtian is the capital of great importance. Youliang Chen, the invading enemy is stronger than Zhu.

Objectives: Zhu summoned his advisers for counsel. Most of them suggested to abandon Yingtian City (that is, to escape). Only the advisor Bowen Liu asserted to stand fast to the city because Yingtian was too important to lose. If they do, they would suffer grave consequences. Yuanzhang Zhu took his advice of confronting the enemy in Yingtian.

Overall guiding ideology: luring the enemy in the deep, and then attacking them by ambush (proposed by Bowen Liu).

Zhu adopted the general guiding ideology put forward by Bowen Liu and designed the specific scheme. Given that his navy was at a disadvantage, he intended to induce the enemy onto the ground, a designated place of his wishes (Longwan, in the northwest suburbs of the city), and to seek to vanquish the enemy by ambush. Zhu would not like to see Chen's navy crossing Qinhuai River to the wall of Yingtian. He made an issue of a wood bridge named Jiangdong Bridge, a pass on Sancha River a route to Yingtian's west wall that could not be bypassed. His intentions were to stop Chen's navy here and make them find their way to Longwan. How to make that happen?

Zhu had a double agent Maocai Kang so he commanded Kang to misinform Chen that Kang himself would come to Chen's aid at Jiangdong Bridge ( a wood bridge). Then Zhu called in his soldiers to dismantle the wood bridge and had $a$ stone bridge built that very night. Chen Youliang led his navy to the stone bridge and landed personally. But Kang was not there. Nobody answered his call. He suddenly began to feel panic when noticing that the bridge was not the wood one as Kang mentioned. Meanwhile, he got the news that 10,000 soldiers of his brother had landed in Longwan in the north of new estuary, and were waiting for the reinforcement after defeating the garrison (see Fig. 5.1). Consequently, Chen decided to turn his army to Longwan to the trap set by Zhu. In such a decisive battle, Youliang Chen had more than 20,000 soldiers' dead, and more than 7,000 soldiers were captured. Zhu seized more than 100 ships, and over 100 boats with barely no losses. ${ }^{1}$

From the perspective of three elements of strategy, Yuanzhang Zhu needs to make decisions on three big questions in the battle. What is the situation (or what is my major problem)? Whether should I evacuate from Yingtian or stay to fight? Moreover, if confronting the enemy, what general guideline should I take to possibly win this battle? The decisions of these three questions are crucial to this battle, which are also the three elements of strategy (Fig. 5.2).

\footnotetext{
${ }^{1}$ Sorted from Things in Ming Dynasty Volume One (2014) written by Dang Nian Ming Yue.
} 
Fig. 5.1 Map of a war between Zhu and Chen

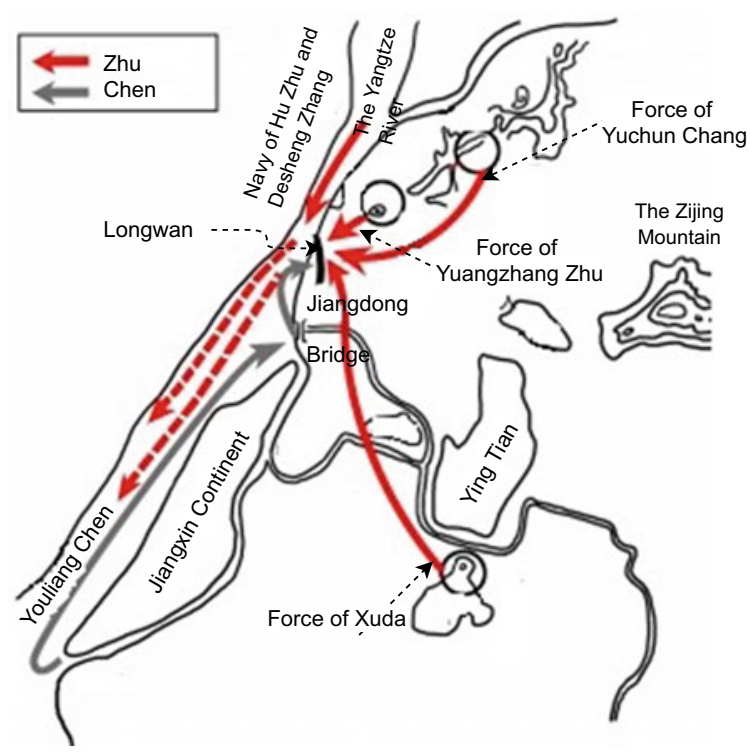

Fig. 5.2 Three Elements of Strategy in Longwan Battle

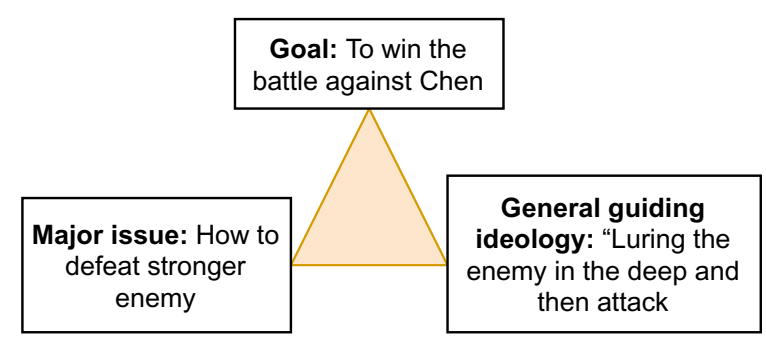

It is obvious that the three decisions are closely connected. If Zhu's adviser Liu Bowen were not confident enough or had no strategic ideas, he would not propose to stay in the city and fight against Chen Youliang. If Zhu had no idea or confidence in the specific scheme, he would not adopt Liu's proposal. As a result, the idea of "luring the enemy in deep, attacking them by ambush" was put forward and specified for the strategic problem of overcoming the stronger enemy in the battle.

However, if we only use the figure above to show the battle, something seems to be missing. The figure does not well present this combat, in absence of tactics playing a part.

Tactics are specific schemes to realize strategic goals and solve significant problems under the guidance of guideline. The writer Dang Nian Ming Yue (which means Moon In Those Years) calls the specific tactics of Zhu's win over Chen as "plan and conspiracy". In this example, tactics have many implications. Zhu was no strong power at that time, and he personally led troops to fight. The guiding ideology "Luring the enemy in deep, attacking them by ambush" required good 
Fig. 5.3 Tactic and the Three Elements of Strategy in Longwan Battle

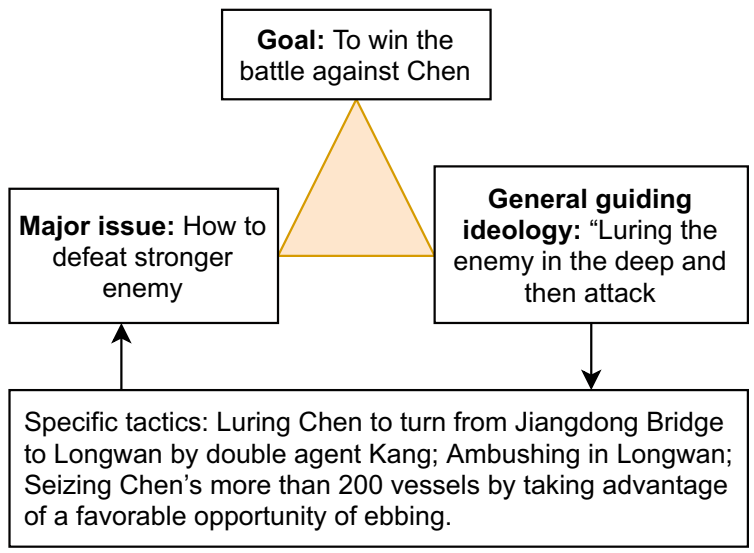

tactics to implement, as to defeat Youliang Chen. Therefore, for Zhu, specific tactics are highly important. Here he employed a set of combined tactics: (1) luring Chen to turn from Jiangdong Bridge to Longwan by double agent Maocai Kang; (2) ambushing in Longwan; (3) seizing Chen's more than 200 vessels by taking advantage of the favorable opportunity of ebbing.

Let's add specific tactical plan to the figure of three elements (see below). Compared to the former one, it fully displays Yuanzhang Zhu and his colleagues' strategic ideas and plans in the battle (Fig. 5.3).

For long tactics seem to be detached from strategies. But we can learn that tactics and strategy are of equal importance in the case of the battle above. The overall guideline of "luring the enemy in the deep, attacking them by ambush" plays a guiding role in developing tactics. The circumstantial and sophisticated (serial combination) tactical scheme fully expressed the strategic ideas.

That is the relationships between strategy and tactical scheme.

Each battle has its particularity; the commander should tailor respective tactics in accordance with distinctive characteristics. Hence, if a strategy is not proposed for a specific battle, but to guide multiple battles in a certain period, specific tactics may not be included in this kind of strategy. The commander of a battle develops and arranges the tactical plan according to the ideologies in the strategic idea.

Tactic and three elements of strategy are introduced above in military. Then how to understand this in a company?

What is the relationship between tactic and strategy in a company? Should tactics be included in the strategy? These two questions are rarely discussed in most academic researches on company strategy, but are critical for strategic plan and its implementation. Now we look at these two questions.

The question of whether tactics should be included in the strategy can be comprehended from the role of strategy at distinct levels of the company. 


\subsection{SBU Level Strategies and Tactics}

Strategies in the level of Strategic Business Unit, or SBU (including branch company and business unit) share similar nature with the battle between Zhu and Chen. Businesses of SBU needs to face competitors in the market, so their strategies are mostly competitive strategies. For what are competitive strategies, please refer to the article Name and Three Elements of Strategy for more information.

Let's look at a specific case of competitive strategy in business by reviewing the silent battle between Taobao and eBay. I will provide some basic information about the case to clarify the relationship between Taobao's competitive tactics and its strategies.

Jack Ma decided to join in the industry when seeing the potential of P2P business in China. How to compete with eBay, an international company who was well-know and had owned more than $70 \%$ market share in China market?

Taobao has set a clear goal: seizing market share from eBay, i.e.to transfer current and new buyers and sellers from eBay to Taobao's platform. Then how to attract people to Taobao's platforms? Clearly, Taobao was facing a crucial issue for competing with eBay. The issue can be eBay is stronger than me. It also can be stated as how to create a platform with more competitive edges than the rival to attract clients (buyers and sellers), which seems a better statement as it seized the core of the competition problem. We know that as a result, Taobao adopted the competitive idea (or general guiding ideology): better quality and reasonable price (also knew as a hybrid strategy), which means to launch a platform with better service quality and economical price compared to eBay. So far, we can learn the three elements of Taobao's competitive strategy, among which the general idea of hybrid is dominant on detailed tactics.

Under the guidance of the hybrid idea, Taobao carried out comprehensive research on eBay's service platform, China's market and psychology of buyers and sellers. Tactics were put forward as following:

(1) A free platform for both buyers and sellers (mine is cheaper than eBay);

(2) A platform that can solve the trust issue between buyers and sellers. Money is first transferred to a medium, Alipay, and will then be transferred to the seller's account after the buyer has received the goods and confirmed the receiving (mine is better than eBay).

(3) A platform on which buyers can communicate with sellers for more information (mine is better than eBay).

(4) A platform with abundant information and joyful pictures that suits Chinese taste for liveliness;

(5) A platform without auction since Chinese people are neither fond of nor familiar with it;

Taobao's competitive strategies, tactics and the relationship between them are summarized in Fig. 5.4. 
Fig. 5.4 Competitive Tactics and Three Elements of Strategy of Taobao's in 2003

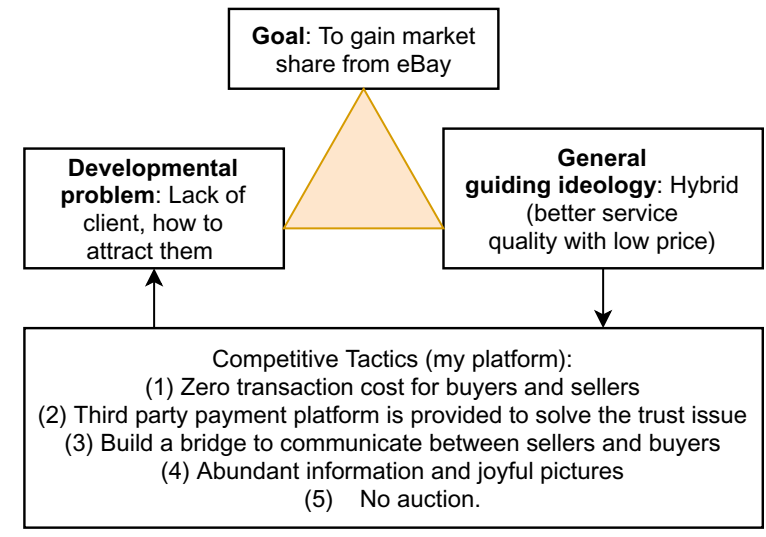

The figure above shows the three elements of Taobao's competitive strategy and its tactic plan. Underneath the triangle, are the specific competitive tactics developed under the guiding thought of hybrid. And these tactics aim to solve the element "major problem" on the bottom left of the triangle. Today's achievement of Taobao shows that its tactics and competitive strategy were correct in 2003, which attracted most buyers and sellers to its platform and constituted a significant threat to eBay.

We see from the battle between Zhu and Chen, and the business competition between Taobao and eBay, strategies and tactics are closely related in both a military and commercial battle. If Zhu and his advisers hadn't come up with a complete and specific ambush tactics, his strategy of defeating would have been superficial and winning over Chen would have been only a daydream. Similarly, if Taobao had not developed a detailed and all-round competitive tactic that meets Chinese customers' demands, its strategic idea of better value for money would not have been successful.

Now let's come back to the questions raised at the very beginning of this chapter. What is the relationship between tactic and the three elements of strategy concept? Should tactics be included in strategies?

Tactics are scheme developed under the guidance of the general guiding ideology to solve the key problems encountered on the path of the long-term goal of the organization. The relationship between tactics and the three elements of strategy can be illustrated in Fig. 5.5. We see from the figure that the element of "general guiding ideology" plays directing role in the development or proposition of tactic scheme. The role of tactics is to resolve the key problems. Hence, tactics can also be understood as a solution scheme to the major problems of an organizational development. The solving of the problem will lead to the achievement of the competitive goal.

We see from above examples that tactics of how to compete are necessary in a company's competitive strategy and should be included in competitive strategy at the level of business unit.

Competitive strategies such as Cost-leadership, differentiation and hybrid are well-knew in academic field. But without the details of tactic scheme, competitive strategy will be broad and will have less practical significance to business operation. 
Fig. 5.5 Relationship of three elements of strategy and tactic in the level of SBU

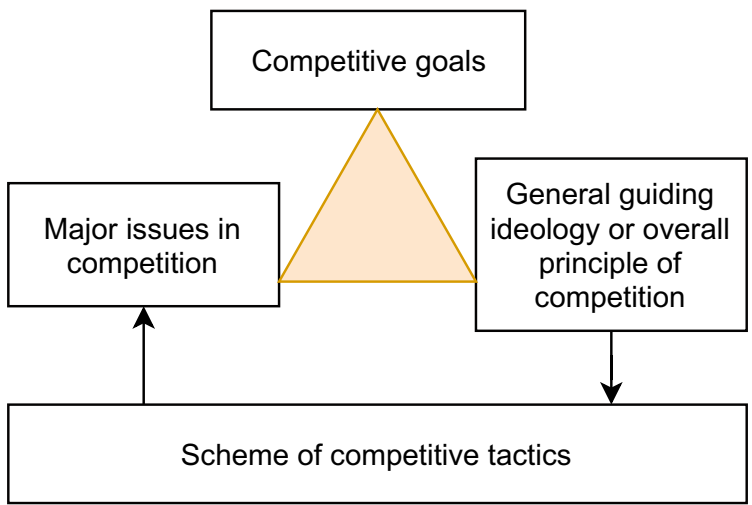

We see from Taobao case, the tactics were proposed after a careful study of the needs of Chinese customers and the service weakness of eBay in China market. Thus a well-developed tactic scheme is crucial for the success of an actual competitive strategy.

\subsection{Strategies and Tactics for Subsidiaries}

Large companies are usually consisted of some subordinate companies. Strategies in large companies can be divided into two categories: one is for guiding subordinate companies' competitive activity and the other is for corporate organization's own use.

We have seen the relationship between tactics and the three elements of strategy in competitive strategies. For strategies at corporate level, this relationship will be same. Hence following we will be more interested in the question of whether tactics should be included in strategy decisions at corporate level. Let's look at the issue with the two cases of subsidiaries.

\section{(1) When subsidiaries own different scopes of businesses}

Generally, if subsidiaries of a company are all based in one place, each subsidiary has different focuses of their businesses. Take Shanghai Electric Corporation as an example, its subsidiaries are nearly all located in Shanghai, including Electric Power Transmission and Distribution Group, Electric Nuclear Power Group, Automation Division, Mechanical and Electrical Company, Electric Group Environmental Protection, Electric Wind Power Group, Electric Finance and Electric Insurance Broker. Although all in power equipment field, these branches vary in business scopes from nuclear power, thermal power, wind power, to finance and insurance industry.

Different industry dictates different competition situations in each subordinate company faces. For example, in the industry of wind power equipment, in the first half of 2015, China had started 270 new wind farm projects, with a total of 5474 newly installed machines and the 10.1 million kilowatts installed capacity, and reached a year-on-year increase of $40.8 \%$. Main manufacturers include Gold Wind 
Technology, Sinovel Wind Power, Mingyang, United Power, Yunda, CSR, Xiangtan Electric Manufacturing, and Dongfang. However, despite the large number of manufacturers, several enterprises only pursued single unit capacity, and new models are quickly released. The companies in the industry pay little attention to the introduction and digestion of technologies, re-innovation ability, and product quality, thus lacking the core technologies such as the overall design of wind turbine, load optimization calculation, control strategy optimization, and grid-connected performance, resulting in the unstable quality of some wind turbines and some quality accidents. The industry needs to improve technologies, and further enhance unit design quality and manufacturing quality (Yu Haijiang 2015). In accordance with the characteristics of Michael Porter's industry life cycle, the industry is still in the early stage of development.

But in the design and manufacture of thermal power equipment, China owns the largest amount of (ultra) super-critical units in the world, with mature and advanced technologies, and some world-class level equipment and technologies. Therefore, although all within the power industry, the respective technological and competitive environments of wind power and thermal power are different.

Subsidiaries of Shanghai Electric Corporation are running different businesses, so it will be not appropriate for the corporation to use a unified competitive strategy (or tactics) to guide all its subordinate enterprises. Consequently, under the guidance of the head office, the branch managers can develop their own tactics according to the competition situation, and their own resources and ability.

Thus, when subordinate subsidiaries are in different industries, the corporate generally will not use a unified detailed tactical program to guide the subsidiary competitive tactics. Or detailed tactic scheme may not be included in the corporate strategies.

There are occasions that executives may personally be interested in the tactics of some subsidiary's business due to their importance. Under this circumstance, tactics may be included in the strategies of guiding subsidiary's business development.

\section{(2) When subsidiaries own similar scope of business}

If subsidiaries focus their business on the same area as that of the corporate company, they are usually located in separate places. For example, General Motors owns the Asia-Pacific branch, the European branch, the US branch, and the AsiaPacific branch also includes the Chinese branch and the Indian branch, etc.

Soon you will find that the politics, economy and culture environments of the areas that GM set branches in are not the same. For example, sales of passenger cars in Europe have declined continuously for five years from 2009 to 2013 influenced by the US financial crisis and European debt crisis, until a slight rise in 2014. While in China, compared with 2008, China's passenger car growth rate was 59\% in $2009 .{ }^{2}$ In addition, within the industry, the characteristics of consumers in different

\footnotetext{
${ }^{2}$ China's passenger car sales reached 10.26 million in 2009, increasing 59\%, Statistics from Tencent Car on January 10, 2010.
} 
Fig. 5.6 Corporation's strategy that instructs the subordinate

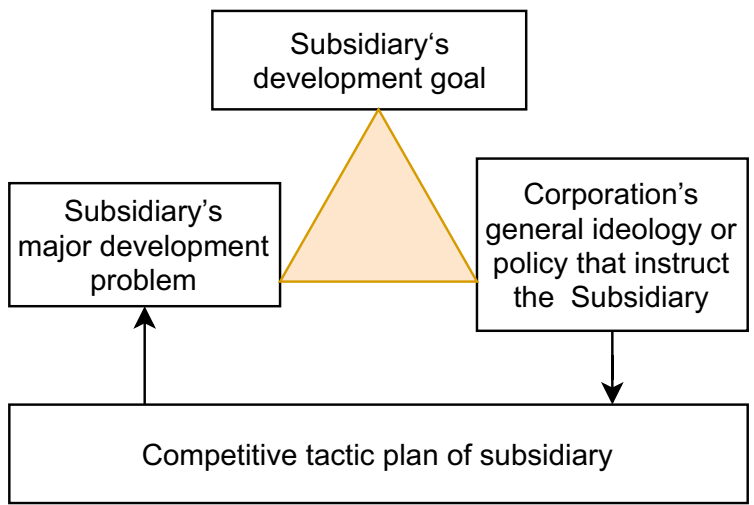

regions will be not alike. Let's take the family as a unit. Many European consumers make repeating consumption. But in 2009 for many Chinese families, it was the first time to buy a car. Consumers had little knowledge of the brand, performance, etc. Besides, Chinese government attaches great importance to the automobile industry, regarding it as a pillar industry of national economic development. So even in the same period, auto markets in Europe and China show different characteristics in the politics, economy and consumer groups.

It is feasible for the GM top level executives to make instructional strategies for each subordinate while a uniform tactic for all may do not make senses. Detailed competitive tactics can be made by the subordinate according to local situations at that certain time and implemented after gaining approval. ${ }^{3}$

Also, there are occasions that executives may personally be interested in the tactics of some regional branch's business due to their importance. Under this circumstance, tactics may be included in the strategy decision of guiding branch subsidiary's business development.

The relationship between strategies and tactics for guiding subordinates can be concluded as Fig. 5.6.

\subsection{Strategies at the Corporate Level and Tactics}

Not like the competitive strategy, mergers and acquisitions, diversification, forward integration, and backward integration strategies are usually proposed at the corporation level for the company's development, instead of instructing subsidiary branches.

So is it necessary for tactics to be included in the strategy decision? I will look into a specific example of mergers and acquisitions (M\&A).

\footnotetext{
${ }^{3}$ Here are only inferences for analysis. Whether should subordinates' competitive tactics be made by themselves or by the corporation varies in different companies' practices. Further research can be made on this including the way of making tactics and its degree of satisfaction.
} 
In media coverage, there are few practical examples of companies with all information of the three elements of strategy (goals, major development problems, and general ideology) and tactical information. I found an example from the Internet that was not concerned by media and researchers. This example contains rich information I need. I will introduce this case combined with three elements and the relationship between strategy and tactics. ${ }^{4}$

Great Wall Energy, subsidiary of China Great Wall Computer Shenzhen Co., Ltd. (Great Wall Computer, stock code 000,066) entered the photovoltaic industry in 2009. The company draw up a development strategy in 2010, hoping to gain access to the advanced technologies in the field through M\&A. I found the strategic plan ${ }^{5}$ made by the company's strategy department and the business management department on the network. The main contents of the plan are as follows.

Aim of the M\&A.

To complement and synergy with the Great Wall Yituo's solar photovoltaic and computer power business, thus having higher capital gains.

General guiding ideology of the M\&A.

To implement the Great Wall's emerging energy industry development plan, choose enterprises with certain achievements in solar photo-voltaic industry as the platform for Great Wall development in this industry. Acquire those having outstanding R\&D capabilities to provide technical support for the company's new energy strategy, and especially for photo-voltaic industry. The subdivisions include the inverters, polysilicon battery (from the polysilicon slice) and component products.

Requirements of the targeted company.

Mature R\&D team, leading R\&D technologies, recognized performances, appropriate size, advanced manufacturing management technologies, weak brand channel, potential to go public, leading R\&D and manufacturing capabilities in the industry and certain extents of scale and profitability.

Ways of $M \& A$.

Holding controlling interest as priority, buy in shares in the second place; and industrial investment in the first place, capital gains in the second.

In addition, the plan listed the tactic details of the $\mathrm{M} \& \mathrm{~A}$ strategy.

As can be seen from the above, there are clear goals (objectives) and general guiding ideology in the plan. We know that the ideology is used to guide the specific M\&A tactics. So this plan has these two elements of "strategic goals" and "general ideology". Ways of M\&A in the plan are also directive, and therefore can be divided into the overall guiding ideology. The plan does not reveal the statement and description of the company's development problems. But we can infer from the purpose of its acquisition and general guiding ideology that its development problem is the lack of a platform with $R \& D$ and technical strengths in the photo-voltaic industry which can help the company achieve the goal.

\footnotetext{
${ }^{4}$ Here I only introduce the content but do not comment on the case.

${ }^{5}$ Here the strategic plan refers to a scheme, which consist of the decisions of three elements of the strategy plus its tactic.
} 
Under the guidance of strategic goals and general idea, the company developed a specific M\&A tactics.

Figure 5.7 shows the relationship between the tactics and the three elements of strategy of the Great Wall's photo-voltaic M\&A example. Tactics, including the product, marketing and those enhancing the company's core competencies, are formed under and in line with the general guiding principles of the M\&A, and serve for solving the company's "major problems" in development.

The traditional strategy will regard "M\&A" and "acquisition" as a strategy, in fact, "M\&A" or "acquisition" are only names. In Fig. 5.7, the three elements of strategy have rich contents. M\&A overall idea on the bottom right provides ideological guidance for the specific M\&A tactics, and tactics below the triangle are specific plans and programs proposed to solve the company's development problems under the guidance of the guidelines.

In the above example, tactics are clearly and exhaustively included in the strategy. How can we understand this phenomenon? Should all corporate strategies include tactical programs?

The detailed content of the Great Wall PV business M\&A example came from the strategic plan jointly drafted by the company's strategy department and business administration department. This plan is made by the company's middle-level management. However, decisions of the three elements of strategy in this case should come from senior managers. If we wish to answer the question "whether tactics should be included in the strategy", we can look at the circumstances of the decision-makers and decisions.

If strategic decision are from company's top level, and executives do not work out tactics personally, rather they repay on subordinates to develop the detailed tactics, then tactics can be excluded from the strategic decisions by top executives. Alternatively, when the same person or team, specific tactics do not make the strategy and tactics can be not included in the decisions by the top-level decision maker(s). But tactics should be included in the strategy in both of the following cases. Tactics should be included in the strategic plans made by company's middle level managers. In addition, when the decision-makers of tactics and of the three elements of strategy are the same, specific tactical programs (or plans) should be included in the strategy plan. ${ }^{6}$

For other corporate strategies (such as diversification and integration), their tactics have similar relationship with three elements of strategy like in the case of the above M\&A strategy. More information on these strategy names can be found in the Chapter Name and Three Elements of Strategy. Here the M\&A strategy is only to illustrate the relationship between three elements of strategy and tactics.

The relationship of the three elements and tactics at the corporation level for self-use is concluded as Fig. 5.8.

\footnotetext{
${ }^{6}$ Further study could be conducted to help us understand under what circumstances the company strategies and decisions contain the three elements and the specific tactical plans simultaneously.
} 


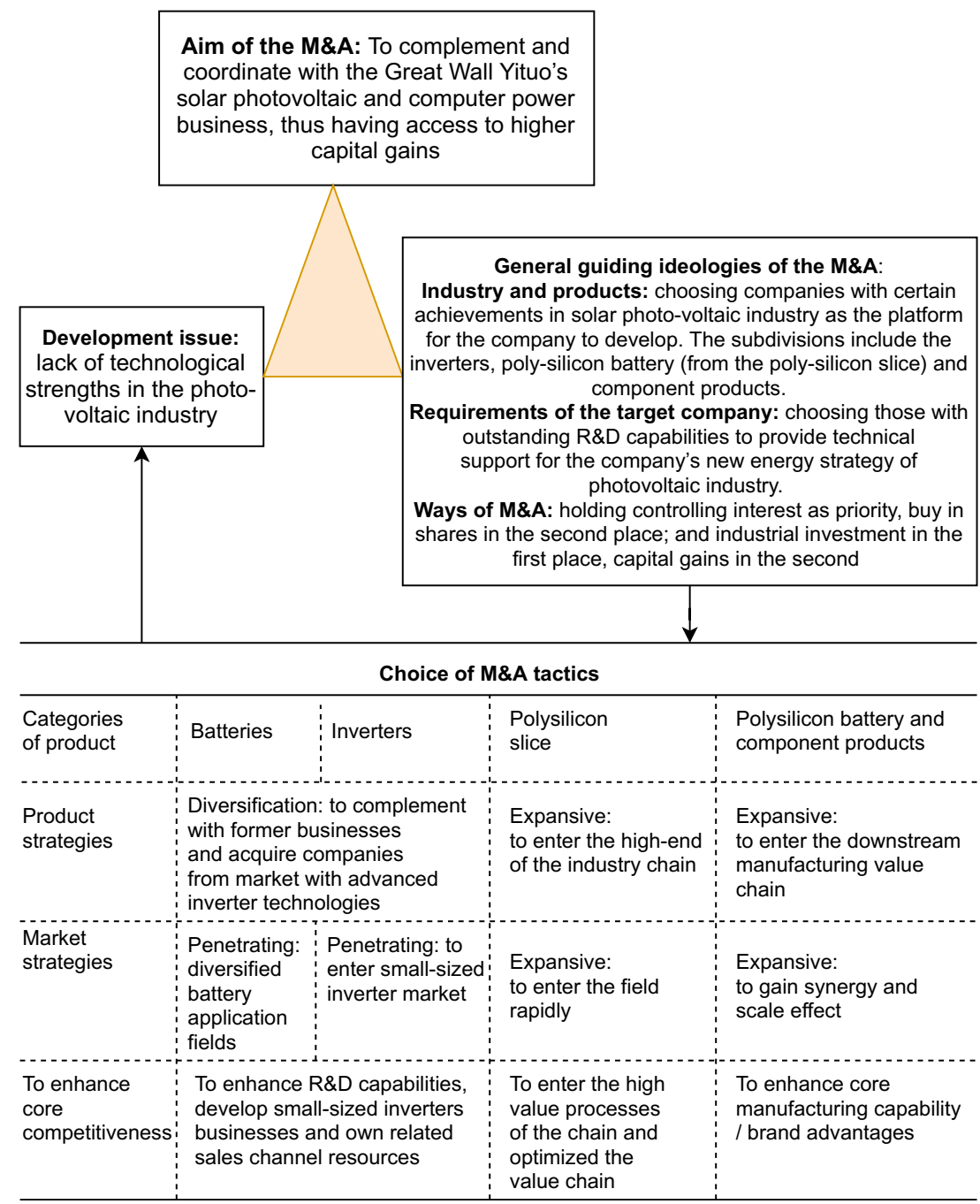

Fig. 5.7 Strategies and tactics in the Great Wall's Photo-voltaic M\&A

Thus whether the corporate strategy contains tactics (or tactic programs) will depend on the object they serve. If the strategy is for guidance for subsidiary, it may not include specific tactics. The branch managers tend to be more familiar with the possible objects, products and other information. So specific tactic programs can be drawn up by the branch, and then be reported to the corporation for approval. However, the strategy of the group company's own use in general needs a tactical plan. 
Fig. 5.8 The relationship of strategy and tactics at the corporation level

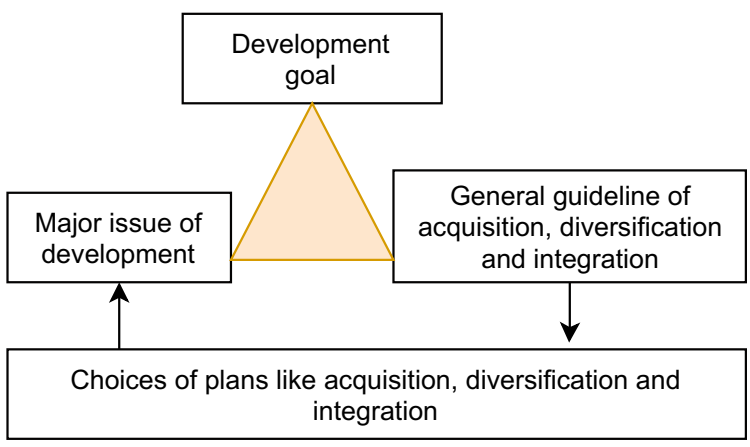

Table 5.1 Summary of whether corporation level strategy needs to include tactics

\begin{tabular}{|c|c|c|c|}
\hline $\begin{array}{l}\text { Aim of } \\
\text { strategy }\end{array}$ & $\begin{array}{l}\text { Whether } \\
\text { contains the } \\
\text { three elements of } \\
\text { strategy }\end{array}$ & $\begin{array}{l}\text { Whether } \\
\text { contains tactics } \\
\text { (or tactic } \\
\text { programs) }\end{array}$ & Notes \\
\hline $\begin{array}{l}\text { Guiding } \\
\text { competitive } \\
\text { strategy of } \\
\text { subsidiary }\end{array}$ & Yes & Not necessary & $\begin{array}{l}\text { When subsidiaries own different } \\
\text { business scopes or are located in } \\
\text { different places, they can make } \\
\text { tactics themselves and report to } \\
\text { the corporation }\end{array}$ \\
\hline $\begin{array}{l}\text { Guiding other } \\
\text { strategies for } \\
\text { subsidiary }\end{array}$ & Yes & Not necessary & $\begin{array}{l}\text { Subsidiaries make tactic programs } \\
\text { themselves and report to the } \\
\text { corporation }\end{array}$ \\
\hline \multirow{4}{*}{$\begin{array}{l}\text { Corporate } \\
\text { own-use }\end{array}$} & Yes & Not necessary & Made by the top level managers \\
\hline & Yes & Yes & $\begin{array}{l}\text { Made by the medium level } \\
\text { managers }\end{array}$ \\
\hline & Yes & $\begin{array}{l}\text { Depending on } \\
\text { the } \\
\text { decision-maker }\end{array}$ & $\begin{array}{l}\text { Decisions on the Three elements } \\
\text { of strategy and tactics are made by } \\
\text { different people }\end{array}$ \\
\hline & Yes & Yes & $\begin{array}{l}\text { Decisions on the Three elements } \\
\text { of strategy and tactics are made by } \\
\text { the same people }\end{array}$ \\
\hline
\end{tabular}

Through the analysis of the three elements of strategy and the tactics at the corporation level, we can summarize Table 5.1.

\subsection{The Relationship Between Strategy and Tactics}

The word "strategy" comes with the meaning of guidance and generality. "Strategy" is important as shown in the examples of the war between Yuanzhang Zhu and Youliang Chen, as well as the M\&A of Great Wall PV business, where it played a significantly guiding role. 
Strategy owns characteristics of overall coherence and guidance. In contrast, tactics are approaches, plans or programs. Generally speaking strategic ideology come in the first place and play a guiding part to tactical programs, while tactics help resolve major development problems and help achieve the strategic goals.

It is noteworthy that in reality, sometimes, the overall guiding ideology of strategy is gradually formed in various tactical practices. Some are even developed and summed up in the lessons of failures. It is not always that the strategy comes first, and the tactics appear later. That is to say, insights of strategic thinking is not a one-step design, but gradually formed from practice and learning.

Let us look at a military example. In the early period of the revolution of the Communist Party of China (CPC), the military strength of the CPC is weaker than that of the Kuomintang. The Communist Party has accumulated rich tactical experience in more than three years of guerrilla warfare. On April 5, 1929, Mao Zedong drafted the "Letter to the Central Committee" in Ruijin, and he said in a letter, "The tactics we have obtained from the struggle for three years are really different from those of the ancient and modern times. With our strategy, the mass struggle is launched more and more day by day, and any powerful enemy is nothing we can do. Our strategies are guerrilla warfare. Main points are: divide out forces to arouse the masses, concentrate our forces to deal with the enemy. The enemy advances, we retreat; the enemy camps, we harass; the enemy tires, we attack; the enemy retreats, we pursue ${ }^{7} \ldots \ldots$. This guideline had been used for three years".

The 16 character guidelines are known as the core general guiding ideology for the guerrilla warfare. We can see from above Chairman Mao's letter, it was accumulated in many guerrilla wars.

Some strategies are developed and summed up in the lessons of tactic failure. We know that Microsoft entered in China in 1992. It had a big development issue due to counterfeit copies. How to translate the market share into revenue? After continuous failures by adopting precepts that had led to its success in the U.S. and Europe, it finally realized that their strategies charging hundreds of dollars for its Windows operating system and Office applications were not correct for a market that a consumer's average income was only US \$301 annually. A new strategy suitable for the Chinese market was formed. "It took Microsoft 15 years and billions of dollars of lost revenue to learn how to do business in China" (Kirkpatrick 2007).

Based on above, we can sum up the relationship between three elements of strategy and tactics as follows: the guiding ideology in the strategy is to serve tactics, and tactics are plans aiming to solve major problems in achieving development goals. We can interpret that the total solution of major problems which can help companies to achieve their long-term goals are composed of two major parts, the overall guiding ideology and the tactic plan under the guidance of the ideology.

From implementation point of view, a strategy at corporate level should include tactic plans. A strategy without tactic plans cannot be enforced.

\footnotetext{
${ }^{7}$ Know as the 16 character guideline in Chinese.
} 


\subsection{Vocabularies Related to Tactics in the Strategic Definition Literature}

By studying the relationship between tactics and strategy, we can see their differences. Tactics are specific programs, schemes and plans under the guidance of the general guiding ideology which is one element of strategy. In the above examples (the battle between Yuanzhang Zhu and Youliang Chen in Longwan, competition of Taobao and eBay), interlinked tactics are implemented to solve development issues.

In the exposition of relationship of tactic and strategy, it came to me that various terminology and vocabulary are used in the literature regarding strategy definition, especially the element of the "general guiding ideology" that locates at the bottom right of the strategy triangle.

The terms describing the element of "general guiding ideology" are muddled with ambiguous expressions in strategy definition literature, like choice of programs or plans, actions, means, how, major policies and plans, approach, moves, programs etc., which can be divided into the following categories.

One has the character of instructive, such as "guiding principles, major policies and etc."

Second has the property of tool such as "means, approaches, solution, how, and etc."

The third has the nature of solution or tactic plan such as "plan, actions, programs, and etc."

If we make a careful analysis on those terms, we can find that the third category (programs, plans, and actions) are different from the first one of "guiding principles" and "policies". "Guiding principles" and "policies" are overarching and instructive while "actions", "programs" are detailed content of the plan. Therefore, we can see that the majority of vocabularies in the third categories are inherently tactical. As in the previous section of the war between Yuanzhang Zhu and Youliang Chen, "luring the enemy into the deep and then attacking them by ambush" is the overall ideology showing profound thoughts. How to realize the ideology is a tactical plan. Although there is a meaning of "approach or tool", the meaning of the second category of terms is somewhat close to the meaning of the first category.

In part of the strategy definition literature, the concept of strategy is defined by tactical terms, adding more complexity to the strategy definition.

Competitive strategies in their meaning contain the basic ideologies of how to compete. However, some corporate strategies do not bear the guiding thoughts of the strategy. In order to develop a feasible strategy, decision-makers are required to put forward an overall guiding ideology that fits the practical business environments and company own resource and capability situation to direct tactics. 


\section{References}

Kirkpatrick, D. (2007, July 17). How Microsoft conquered China. Retrieved from https://money. cnn.com/magazines/fortune/fortune_archive/2007/07/23/100134488/index.htm?postversion= 2007070910.

Yu, H. (2015, Aug 28). Wind power equipment industry lacks core competitiveness of technology: a dominant problem. Retrieved from https://news.bjx.com.cn/html/20150828/657787.shtml.

Open Access This chapter is licensed under the terms of the Creative Commons Attribution 4.0 International License (http://creativecommons.org/licenses/by/4.0/), which permits use, sharing, adaptation, distribution and reproduction in any medium or format, as long as you give appropriate credit to the original author(s) and the source, provide a link to the Creative Commons license and indicate if changes were made.

The images or other third party material in this chapter are included in the chapter's Creative Commons license, unless indicated otherwise in a credit line to the material. If material is not included in the chapter's Creative Commons license and your intended use is not permitted by statutory regulation or exceeds the permitted use, you will need to obtain permission directly from the copyright holder.

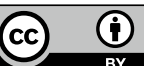

